\title{
Microsurgical Outcome of Post-traumatic Peripheral Nerve Injuries: An Experience of 23 Cases and Review of Literature
}

\author{
Kanwaljeet GARG, Sumit SINHA, Guru Dutta SATYARTHEE, Deepak AGARWAL, Deepak Kumar GUPTA, \\ Bhawani SHARMA, Ashok Kumar MAHAPATRA
}

All India Institute of Medical Sciences, Department of Neurosurgery, New Delhi, India

\section{ABSTRACT}

AIM: The present study aimed to evaluate the microsurgical outcome in post-traumatic peripheral nerve injuries and its correlation with time since injury and the type of the operative procedure performed.

MATERIAL and METHODS: All the patients admitted to our center with the diagnosis of post-traumatic peripheral nerve injury were included in the study. The data of all patients was retrospectively analysed from the computerized database of our hospital. The time period of the study was from January 2008 to March 2011.

RESULTS: A total of 23 patients were included in the study. The interval between injury and surgery was 28.8 weeks (range: 1 day - 70 weeks). The most common mode of injury was road traffic accidents ( $39 \%, n=9$ ). The mean follow up was $24.7 \pm 11.3$ months (range 9-45 months). Six (60\%) patients had a good outcome. There was no statistically significant correlation between outcome and time since injury or type of operative procedure performed $(p>0.05)$.

CONCLUSION: Post-traumatic peripheral nerve injury is a rare form of nerve injury. There is no correlation between the surgical outcome and time since injury. Some of the nerves have a better outcome as compared to others.

KEYWORDS: Peripheral nerve, Nerve injury, Neurapraxia, Axonotmesis, Neurotmesis

\section{INTRODUCTION}

Peripheral nerves were first distinguished from tendons by Herophilus in $300 \mathrm{BC}(11)$. He traced the peripheral nerves to the spinal cord and found the continuity of the nervous system (14). Rhazes was the first author who mentioned nerve repair in 900 AD. Cruikshank demonstrated nerve healing and recovery of distal extremity function after nerve repair in 1795. Cajal is the pioneer of the concept that axons regenerate from neurons and are guided by chemotrophic substances (11). In 1945, Sunderland promoted microsurgical techniques for the repair of nerve injuries and achieved good clinical outcomes (14). Then, many advances and new concepts were developed in peripheral nerve reconstruction. Researches on the molecular basis of nerve injury increased and new strategies improved the results of nerve repair (11). However, there is yet no proven technique that will hasten nerve regeneration or accelerate the growth of regenerating axons along the nerve sheath (1).

Currently, nerve injuries are mostly secondary to motor vehicle accidents, blast and fire arm injuries. The most common type is the closed and traction type nerve injury (1). Other causes include falls, post surgical and post injection, post-irradiation and knife cuts etc.

The present study aims to evaluate the microsurgical outcome in peripheral nerve injuries and its correlation with time since injury and the type of the operative procedure performed.

\section{MATERIAL and METHODS}

All the patients admitted to our center with a diagnosis of posttraumatic peripheral nerve injury were included in the study. 
The data of all these patients was retrospectively analysed from the computerized database of our hospital. The period of the study was from January 2008 to March 2011. The age of the patients ranged from 9 years to 52 years (Mean $\pm S D$, $32.2 \pm 12.4$ years) with the majority $(61 \%)$ belonging to the age group of 20- 39 years. (Figure 1) There were $83 \%(n=19)$ males and $17 \%(n=4)$ females (Figure 2$)$. The median nerve was the most commonly involved nerve in our series (Figure 4). All the patients with birth injuries, post irradiation injuries and malignant infiltration in neck, axilla or back and groin were excluded from the study. A detailed history including mode of injury, with thorough clinical examination and record of neurological examination i.e. motor, sensory and autonomic deficit, were recorded in a pre-designed proforma. Muscle power grading was done using British Medical Research Council grading (1 to 5). Imaging (such as X-ray chest, neck, shoulder, lumbosacral spine and pelvis) was obtained for bony fractures or dislocations associated with nerve injuries. The electrophysiological studies included nerve conduction velocities to specify the site and extent of nerve injury; and electromyography (EMG) to confirm the neurogenic type and to rule out the muscle disease as a cause of weakness (1).

Post-operatively, the paralyzed limb was kept immobilized in optimal functional position for a period of 4 weeks, after which

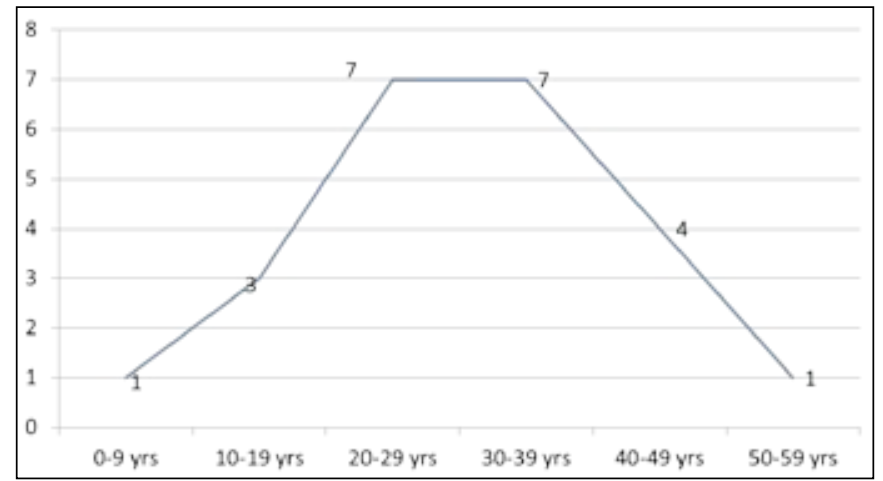

Figure 1: Graph showing age distribution of patients.

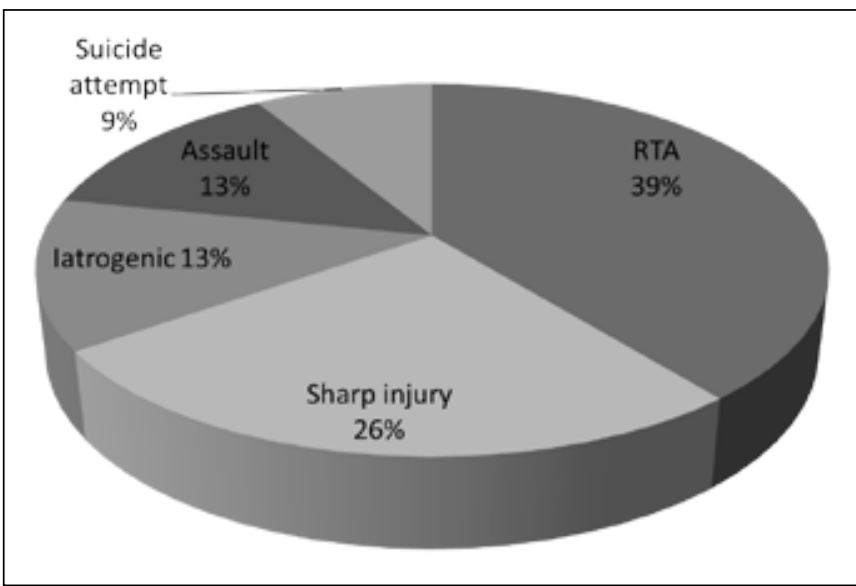

Figure 3: Pie chart showing mechanism of injury (RTA = Road traffic accident). the physiotherapy was started. The primary endpoint of the study was improvement in the motor power of the affected muscle groups. The surgical outcome was analysed on the basis of Medical Research Council grading into good outcome $(\geq 3 / 5)$ and poor outcome $(<3 / 5)$. All analyses were performed using the statistical program SPSS version 17. Percentages were compared using the chi square or Fisher exact test. For intergroup comparison, the Student t-test was used for parametric data. Probability values $<0.05$ in these analyses were considered statistically significant.

\section{RESULTS}

During the study period, a total of 240 post-traumatic nerve injury patients were operated at our centre, out of which 23 patients $(10 \%)$ were post-traumatic peripheral nerve injuries. The interval between injury and surgery was 28.8 weeks (Range: 1 day-70 weeks). The most common mode of injury was road traffic accidents $(39 \%, n=9)$. Other common modes of injury included injury by sharp objects, iatrogenic injuries or assault (Figure 3). Two patients had a wrist slash injury.

Early surgical intervention i.e. within 6 months of injury was done in $56 \%$ of patients and the rest were operated 6 months after injury. Neurolysis was done in 12 patients (52\%) and 11

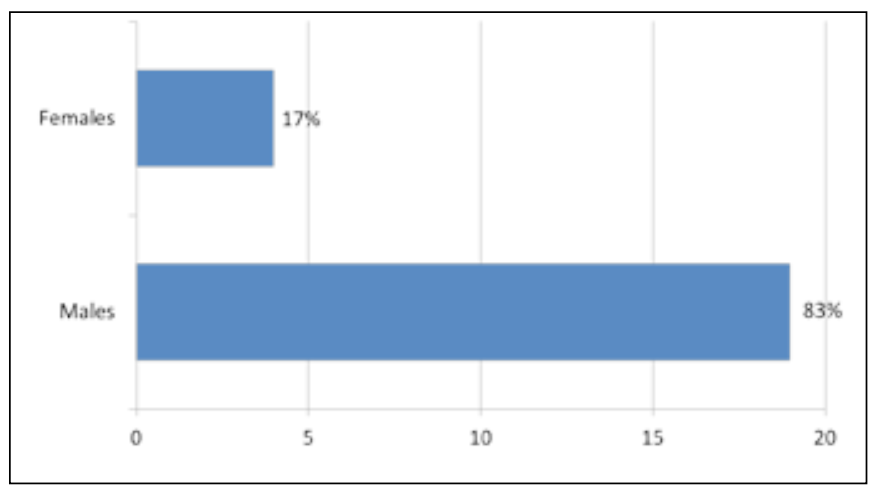

Figure 2: Graph showing gender distribution of patients.

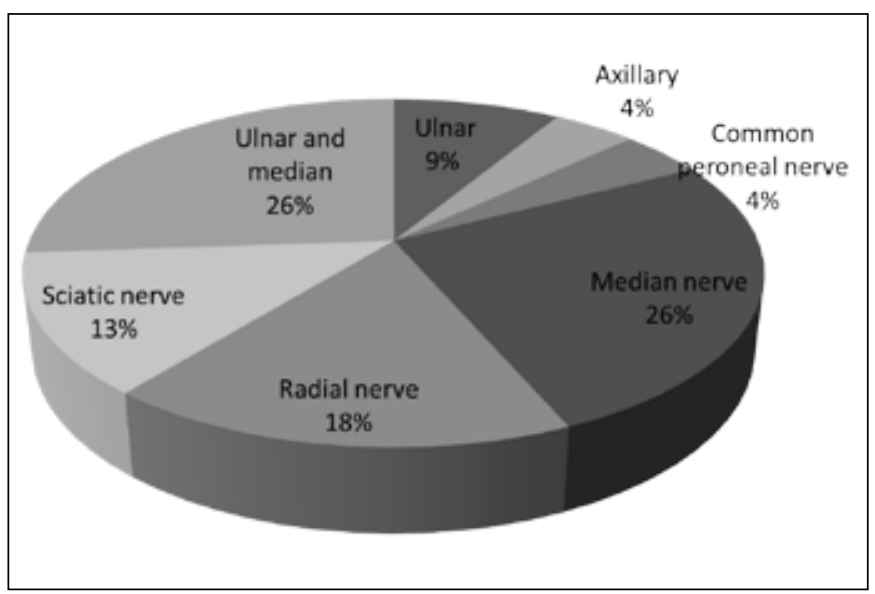

Figure 4: Pie chart showing distribution of different nerves involved. 
(48\%) underwent primary nerve repair, either by using cable grafts from the sural nerve (10 patients) or direct end-to-end anastomosis (one patient) (Figure 5). The mean follow up was $24.7 \pm 11.3$ months (Range: $9-45$ months). Out of the 10 patients who could be followed up, 6 patients $(60 \%)$ had a good outcome (regained motor power $\geq$ M3) (Table I). Table

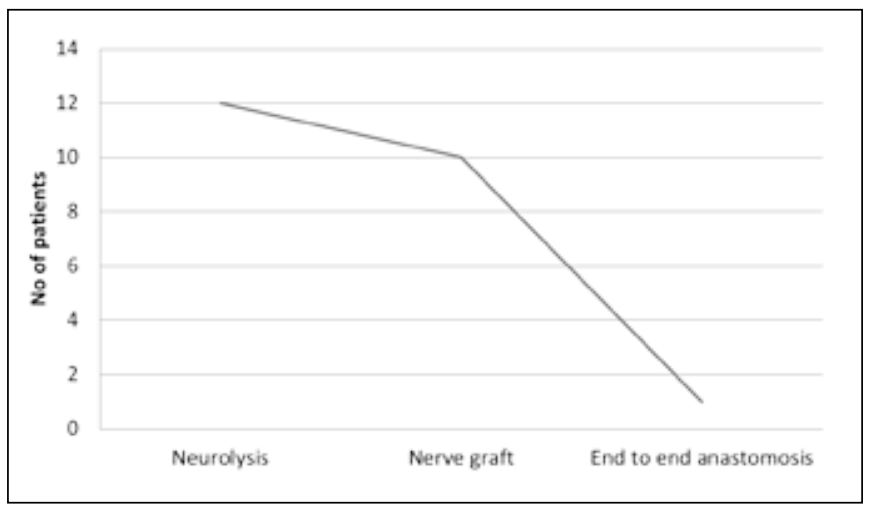

Figure 5: Graph showing different procedures done.

Table I: Outcome as seen in Our Patients

\begin{tabular}{lc}
\hline Outcome & No of patients \\
\hline Good outcome & $6 / 10$ \\
\hline Poor outcome & $4 / 10$ \\
\hline
\end{tabular}

II shows the rate of improvement with respect to the different nerves involved. There was no statistical significant difference in the outcomes of patients operated within 6 months of injury or those after 6 months (Table III) and the type of operative procedure (Table IV).

\section{DISCUSSION}

The most common causes of nerve injuries are traffic accidents, blasts and fire-arm wounds. Stretch-related injuries are the most common type of nerve injuries (1).

Peripheral nerves have an inherently elastic structure because of their collagenous endoneurium. However, the nerves are prone to injury when traction forces exceed the nerve's capacity to stretch. If the force is great enough, the nerve continuity may be disturbed as seen in brachial plexus avulsions (2). However, the continuity is retained. This type injury can be isolated (Erb palsy and similar brachial plexus birth-related injuries) or associated with extremity fractures where the peripheral nerves and the bones are in close relationship (radial nerve injury following humeral fracture) (2). Lacerations by knife blades are another common causes of peripheral nerve injuries (2). Whereas these can be complete transections, more often some nerve element of continuity remains.

Compression is a third common type of peripheral nerve injury. Some of the compression injuries include the "Saturday Night palsy" due to radial nerve compression and entrapment neuropathies. There is no severance or tearing of the neural

Table II: Outcome in Different Nerves

\begin{tabular}{lcccc}
\hline & No of patients & Follow up & Improved & Not improved \\
\hline Median & 6 & 4 & 2 & 2 \\
\hline Sciatic & 3 & 2 & 1 & 1 \\
\hline Ulnar & 2 & 1 & 1 & 0 \\
\hline Axillary & 1 & 1 & 1 & 0 \\
\hline Radial & 4 & 1 & 1 & 0 \\
\hline Ulnar and median & 6 & 1 & 1 & 0 \\
\hline
\end{tabular}

Table III: Outcome with Respect to Interval Between Injury and Surgery

\begin{tabular}{lccc}
\hline & Improved & No improvement \\
\hline Within 6 months $(n=13)$ & 2 & 1 & \\
\hline $6-12$ months $(n=10)$ & 4 & 3 & $p=0.78$ \\
\hline
\end{tabular}

Table IV: Outcome with Respect to Type of Surgery Performed

\begin{tabular}{lccc}
\hline Type of surgery & Improved & Not improved & p value \\
\cline { 1 - 3 } Neurolysis & 4 & 2 & 0.6 \\
\cline { 1 - 3 } Nerve graft & 2 & 2 & 0.6 \\
\hline
\end{tabular}


elements in compression injuries (2). In our study, 52\% of the patients had stretch injuries and $48 \%$ had penetrating injuries.

The timing and success of the peripheral nerve repair process mostly depends on the extent of injury. Clinically grading systems which allow correlation of the microscopic changes in the nerve after injury and patient symptomatology are currently in use $(2,13)$. The commonly used grading scales have been developed by Seddon (13) and Sunderland (14).

Sunderland's classification stratifies the three injury types described by Seddon into five categories according to severity (14). A first-degree injury is equivalent to Seddon's neurapraxia and a second-degree injury is equivalent to axonotmesis and third-degree nerve injuries occur when there is disruption of the axon (2).

In a large compilation of data from patients with peripheral nerve injury over a 40-year period, Mackinnon and Dellon reported that very good results $(\mathrm{M} 4, \mathrm{~S} 3+)$ were obtained in approximately $20 \%$ to $40 \%$ of cases (9). They also concluded that very few injuries recovered fully, and war injuries generally did worse.

A more recent series of primary repairs and fascicular grafts in 132 patients with median nerve injuries showed good to excellent results in 47 of 98 patients (48\%) treated with grafting and in 17 of 34 patients (50\%) treated with secondary neurorrhaphy (4). Overall, 65 of 132 patients (49\%) had good to excellent results, $14(11 \%)$ had fair results, and $53(40 \%)$ had poor results. The authors concluded that the results were poor in four situations: (1) age > 54 years (2) level of injury proximal to elbow; (3) graft length $>7 \mathrm{~cm}$; and (4) surgery delayed more than 23 months.

Similar excellent results in median nerve injury were reported by Novak et al. (12). In our study, 2 out of 4 (50\%) patients with median nerve injury (with follow up) had a good outcome. In a separate series of radial nerve repairs treated with grafting or secondary neurorrhaphy, useful (good to excellent) results have been reported by various authors $(5,15)$. Terzis et al. found that better functional results were achieved in younger patients, with denervation time $\leq 3$ months, lesions in continuity, patients without associated nerve injuries, distal lesions, with neurolysis, and with nerve grafts less than or equal to $5 \mathrm{~cm}$ long (15). In our study, only one patient with radial nerve injury who was followed up, had a good outcome.

Vastamäki et al. (16) reviewed the data on 110 patients after ulnar nerve repair and demonstrated useful recovery in 57 patients (52\%). In our study, the only patient with ulnar nerve injury who was followed up, had a good outcome. Kim et al. studied 654 cases of ulnar nerve lesions and reported functional recoveries of Grade 3 or better in 81 (92\%) of 88 patients who underwent neurolysis, $42(72 \%)$ of 58 patients who received suture repair, and $24(67 \%)$ of 36 patients who received graft repair (6) Kline et al. studied 99 patients with contusion-stretch injuries to the axillary nerve (8). Recovery following suture repairs was a mean grade 3.8 , whereas recovery after 66 graft repairs was a mean grade 3.7. They concluded that operative exploration of axillary contusionstretch lesions is worthwhile in carefully selected cases. If indicated by inspection and intraoperative electrical studies, nerve repair can lead to useful function. Murovic studied 1837 patients of upper extremity peripheral nerve injuries (10). He concluded that median nerve secondary suture repairs did better than radial or ulnar nerve suture repairs, with $78 \%$, $69 \%$, and $69 \%$ of the patients respectively attaining good outcomes. Ertem et al. studied the functional results of nerve repair (median and/or ulnar) in patients with forearm clean-cut injuries (3). They concluded that secondary repairs and young patients had the best prognosis. Yang et al. conducted a meta-analysis to compare the outcomes of repair of a median nerve and ulnar nerve defect with nerve graft and tubulization (17). They found that a median nerve with sensory impairment was associated with improved postoperative prognosis, while an ulnar nerve with motor nerve damage was prone to a worse prognosis and tubulization can be a good alternative in the reconstruction of small defects.

Sunderland analysed surgical outcome following nerve reconstruction (over a period of 40 years) and found better results in young patients, early repairs, single function nerves, distal repairs and short nerve grafts (14). In another study involving 318 operative knee-level common peroneal nerve lesions, the authors concluded that surgical exploration and repair of peroneal nerve lesions achieved good results with timely operations and thorough intraoperative evaluations and longer grafts were correlated with more severe injuries and thus poorer outcomes (7).

The limitation of our study is the small number of patients, that might give rise to fallacious results. Moreover, due to the small sample size, it was not possible to analyze different nerve groups separately. Henceforth, our finding of no difference in the results of surgery within 6 months of injury or after 6 months has to be taken with a word of caution.

\section{CONCLUSION}

Post-traumatic peripheral nerve injury is a rare form of nerve injury and constituted around $10 \%$ of total nerve injuries encountered at our center. There is no correlation between the surgical outcome and time since injury. Some of the nerves have a better outcome as compared to others.

\section{REFERENCES}

1. Buhroo AM: Observations on rehabilitation of peripheral nerve injuries in Kashmir Valley. IJPMR 14: 27-32, 2003

2. Burnett MG, Zager EL: Pathophysiology of peripheral nerve injury: A brief review. Neurosurg Focus 16(5):E1, 2004

3. Ertem K, Denizhan Y, Yologlu S, Bora A: The effect of injury level, associated injuries, the type of nerve repair, and age on the prognosis of patients with median and ulnar nerve injuries. Acta Orthop Traumatol Turc 39: 322-327, 2005

4. Kallio PK, Vastamäki M: An analysis of the results of late reconstruction of 132 median nerves. J Hand Surg $(\mathrm{Br})$ 18: 97105, 1993

5. Kallio PK, Vastamäki M, Solonen KA: The results of secondary microsurgical repair of the radial nerve in 33 patients. $\mathrm{J}$ Hand Surg (Br) 18: 320-322, 1993 
6. Kim DH, Han K, Tiel RL, Murovic JA, Kline DG: Surgical outcomes of 654 ulnar nerve lesions. J Neurosurg 98: 993-1004, 2003

7. Kim DH, Murovic JA, Tiel RL, Kline DG: Management and outcomes in 318 operative common peroneal nerve lesions at the Louisiana State University Health Sciences Center. Neurosurgery 54:1421-1428, 2004

8. Kline DG, Kim DH: Axillary nerve repair in 99 patients with 101 stretch injuries. J Neurosurg 99:630-636, 2003

9. Mackinnon SE, Dellon AL: Surgery of the peripheral nerve. New York: Thieme Medical Publishers, 1988:115-129

10. Murovic JA: Upper-extremity peripheral nerve injuries: A Louisiana State University Health Sciences Center literature review with comparison of the operative outcomes of 1837 Louisiana State University Health Sciences Center median, radial, and ulnar nerve lesions. Neurosurgery 65:A11-117, 2009

11. Noaman HH: Surgical treatment of peripheral nerve injury. In: Rayegani SM (ed). Basic Principles of Peripheral Nerve Disorders, In Tech, 2012:93-132
12. Novak CB, Kelly L, Mackinnon SE: Sensory recovery after median nerve grafting. J Hand Surg Am 17: 59-68, 1992

13. Seddon HJ: Surgical disorders of the peripheral nerves. Baltimore: Williams \& Wilkins, 1972: 68-88

14. Sunderland S: Nerve injuries and their repair: A critical appraisal. New York: Churchill Livingstone, 1991

15. Terzis JK, Konofaos P: Radial nerve injuries and outcomes: Our experience. Plast Reconstr Surg 12:739-751, 2011

16. Vastamäki PK, Kallio PK, Solonen KA: The results of secondary microsurgical repair of ulnar nerve injury. J Hand Surg $(\mathrm{Br}) 18$ : 323-326, 1993

17. Yang M, Rawson JL, Zhang EW, Arnold PB, Lineaweaver W, Zhang F: Comparisons of outcomes from repair of median nerve and ulnar nerve defect with nerve graft and tubulization: A metaanalysis. J Reconstr Microsurg 27:451-460, 2011 